Article

\title{
Preparation and Characterization of Novel PVC/Silica-Lignin Composites
}

\author{
Lukasz Klapiszewski ${ }^{1}$, Franciszek Pawlak ${ }^{2}$, Jolanta Tomaszewska ${ }^{2, *}$ and Teofil Jesionowski ${ }^{1, *}$ \\ ${ }^{1}$ Institute of Chemical Technology and Engineering, Faculty of Chemical Technology, \\ Poznan University of Technology, Berdychowo 4, Poznan PL-60965, Poland; \\ E-Mail: lukasz.klapiszewski@put.poznan.pl \\ ${ }^{2}$ Faculty of Technology and Chemical Engineering, University of Science and Technology in \\ Bydgoszcz, Seminaryjna 3, Bydgoszcz PL-85326, Poland; E-Mail: magwisz@ gmail.com \\ * Authors to whom correspondence should be addressed; \\ E-Mails: Jolanta.Tomaszewska@utp.edu.pl (J.T.); Teofil.Jesionowski@put.poznan.pl (T.J.); \\ Tel.: +48-52-374-90-52 (J.T.); +48-61-665-37-20 (T.J.); Fax: +48-52-374-90-05 (J.T.); \\ +48-61-665-36-49 (T.J.).
}

Academic Editor: Philipp Vana

Received: 13 July 2015 / Accepted: 8 September 2015 / Published: 15 September 2015

\begin{abstract}
An advanced $\mathrm{SiO}_{2}$-lignin hybrid material was obtained and tested as a novel poly(vinyl chloride) (PVC) filler. The processing of compounds of poly(vinyl chloride) in the form of a dry blend with silica-lignin hybrid material and, separately, with the two components from which that material was prepared, was performed in a Brabender mixing chamber. An analysis was made of processing (mass melt flow rate, MFR), thermal (thermogravimetric analysis, Congo red and Vicat softening temperature test) and tensile properties of the final PVC composites with fillers in a range of concentrations between $2.5 \mathrm{wt} \%$ and $10 \mathrm{wt} \%$. Additionally, the effects of filler content on the fusion characteristics of PVC composites were investigated. The homogeneity of dispersion of the silica-lignin hybrid material in the PVC matrix was determined by optical microscopy and SEM. Finally, it should be noted that it is possible to obtain a PVC composite containing up to $10 \mathrm{wt} \%$ of silica-lignin filler using a melt processing method. The introduction of hybrid filler into the PVC matrix results in a homogeneous structure of the composites and positive processing and functional properties, especially thermal stability and Vicat softening temperature.
\end{abstract}


Keywords: polymer composites; poly(vinyl chloride); silica-lignin filler; thermal and mechanical properties; structure assessment

\section{Introduction}

Silica plays a very important role as an active polymer filler. The literature contains very interesting reports indicating the use of both pyrogenic and precipitated silica in the formation of modern polymer composites, e.g., natural rubber [1], polyurethane (PUR) [2], polyethylene (PE) [3], polypropylene (PP) [4], polystyrene (PS) [5], poly(vinyl chloride) (PVC) [6], polyhydroxyethylmethacrylate (pHEMA) [7], poly(methyl acrylate) (PMA) [8], poly(butylene terephthalate) (PBT) [9], acrylonitrile-butadiene elastomer (NBR) [10] or carboxylated acrylonitrile-butadiene elastomer (XNBR) [11], and epoxy resin [12]. Motivation for the use of silicon dioxide as a polymer filler comes primarily from its high thermal stability and the favorable strength properties of the resulting composites.

Natural fiber reinforced polymer composites (NFC) are one of the groups of modern construction materials manufactured with a thermoset and thermoplastic matrix. The natural fiber composites offer specific properties comparable to those of conventional fiber composites, and in many applications these materials successfully replace inorganic fiber composites [13]. For the manufacture of natural filler composites with thermoplastic matrix, high-volume polymers are commonly used, usually polyolefins (PE, PP) or PVC, and to a lesser extent PS, acrylonitrile butadiene styrene (ABS) or biodegradable polymers. The thermoplastic polymeric material used to produce the NFC may be in the form of original granules or recyclates $[14,15]$.

Poly(vinyl chloride) differs from other thermoplastics with regard to the possibility of wide-ranging modification of physicochemical, mechanical and processing properties by applying various processing additives to PVC blends, including fillers. Production of PVC composites containing fillers from renewable materials, including natural plant fibers such as jute, bamboo, sisal, and rice straw [16-19], as well as wood fiber and lignin [20-29], leads to materials with advantageous properties that may be successfully used as construction materials as well as in the automotive and furniture industries.

The properties of PVC composites with natural fillers significantly depend on the natural origin of the filler, its particle size and its aspect ratio, as well as its concentration and the homogeneity of its distribution in the polymer matrix [23,27]. Ping et al. [28] reported that lignin and PVC have a certain degree of compatibility. The smaller the content of lignin, the better the compatibility of the lignin and PVC. With increasing lignin content, the impact strength, tensile strength and bend strength of the PVC/lignin composite material decrease. In [29], PVC composites with two types of lignin—kraft and Alcell ${ }^{\circledR}$ — were used to determine the influence of the type of lignin on the mechanical and thermal properties of PVC. Based on FTIR spectra there was found to be interaction between the hydroxyl group of lignin and the hydrogen of PVC. Composites made from lignin obtained from softwood require a lower processing temperature, which reduced lignin decomposition processes. It was also found that the process of lignin degradation is one of the reasons for the composites' decreased resistance to atmospheric agents.

The worsening of the thermal stability of a thermoplastic polymer matrix as a result of the introduction of natural fillers into compounds containing them [30] is especially important in the case 
of PVC [15]. Due to its relative multipart melt processing and high thermal and shear sensitivity, the production of PVC-based composites, particularly with natural fillers, is a complex technical challenge [15]. The thermal stability of PVC/lignin blends was greatly improved after lignin was treated with copolyacrylate, which improved miscibility between lignin particles and the PVC matrix [31].

The processing, physicochemical, mechanical and dielectric properties are influenced by other modifiers used in PVC blends, including nanofillers. The addition of nanoparticles of zinc and aluminum oxide and calcium carbonate, as well as carbon nanotubes and montmorillonite (MMT) nanoparticles [32-39], also causes an increase in the glass transition temperature compared with the unfilled polymer. Silica, however, is used to improve the permeability of PVC in the form of both films [40] and flexible composite membranes [41]. Silica nanoparticles pre-treated with silane significantly improve mechanical properties of the PVC composite [42].

The properties of PVC can be modified by introducing a hybrid filler into the PVC compound. Possible applications of hybrid composite materials, often consisting of a natural filler such as wood or cellulose fibers and an inorganic nanofiller such as glass fibers, mica, nanotubes or montmorillonite, are widely described in the literature [15,43-47]. The mechanical properties of such composites are strongly influenced by the type of surface chemical modifications of both fillers and the ratio of one filler to the other, the compatibilizers used as well as the processing method [15].

Based on the results of the research reported in [45] it was noted that composites comprising modified wood flour and a filler in the form of MMT have superior tensile strength, flexural strength and flexural modulus, regardless of the content of wood flour in the composite. It was also found that modification of the PVC/wood flour composite with montmorillonite significantly improved thermal stability, hardness and water absorption as well as flame retardancy and smoke suppression $[44,45]$. Results of research on a PVC-based composite containing lignin/ $/ \mathrm{TiO}_{2}$ hybrid filler indicated that, regardless of the presence of $\mathrm{TiO}_{2}$, composites containing up to 7.5 parts by weight of lignin have good mechanical properties, despite the incompatibility of the two components as confirmed in SEM and DSC studies. All PVC/lignin/TiO 2 compounds are also characterized by good processability [48].

Sustainable chemistry and engineering require the development of materials and technologies based on renewable natural polymers. Lignin, as the second most abundant biopolymer and a by-product of the paper industry, fits perfectly with this trend. Very recently, our group has found that lignin is an ideal compound for the modification of silica, leading to the development of a new generation of hybrid materials [49-51]. Unique physicochemical, morphological and thermal properties as well as the chemical activity of silica-lignin hybrid materials open the way for their utilization in a broad spectrum of applications. In this work we decided to use, for the first time, an innovative functional

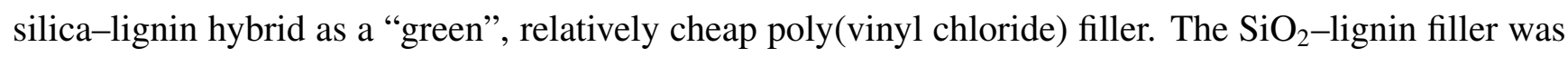
first characterized, and then combined with the PVC. In contrast to the PVC/lignin composite proposed by our research group, a new generation of polymer dual filler should contribute to the improvement of mechanical properties. A very important aspect of this research is also to investigate the role played by lignin as a natural polymer. Lignin, as a low-cost precursor, can be used as a waste material from the process of paper industry. This will provide a way to recycle the problematic by-products of cellulose production, and thus positively influence the environment condition. Subsequently, processing, mechanical (tensile strength, elongation and Young modulus), thermal (thermogravimetric analysis and 
Congo red test) and structural (optical and scanning electron microscopy) properties were examined. This research provides fully innovative and significantly increased knowledge concerning new solutions for the filling of PVC.

\section{Experimental Section}

\subsection{Materials and Methods}

A PVC compound containing S-61 Neralit PVC (Spolana Anwil Group, Neratovice, Czech Republic) (100 wt \%), mixed with 4 wt \% of the organotin stabilizer Patstab 2310 (Patcham, Goor, The Netherlands), and 1 wt \% of Naftolube FTP paraffin wax (Chemson, Arnoldstein, Austria) was used as the matrix of the investigated composites. PVC dry blend was prepared by Anwil Wloclawek.

Three types of materials were used as fillers: the amorphous silica Syloid 244 (W.R. Grace Davison \& Co., USA), kraft lignin (Sigma Aldrich, St. Louis, MO, USA) and silica-lignin hybrid material. This material, containing 20 parts by weight of kraft lignin to 100 parts of Syloid 244 silica, was produced using a mechanical method. The method of preparation of silica-lignin hybrid material and its physicochemical evaluation are described extensively in [51].

The amorphous silica, lignin and silica-lignin hybrid filler were introduced into the PVC matrix at filler concentrations of $0,2.5,5,7.5$ and $10 \mathrm{wt} \%$. Before processing, all types of filler were dried at $105{ }^{\circ} \mathrm{C}$ for $3 \mathrm{~h}$. The compositions of the PVC mixtures and their abbreviations as used in the text are presented in Table 1.

Table 1. The composition of the PVC-based composites.

\begin{tabular}{ccc}
\hline Sample & Filler type & Filler content (wt \%) \\
\hline PVC & - & 0 \\
\hline PVC/S1 & & 2.5 \\
PVC/S2 & silica & 5 \\
PVC/S3 & & 7.5 \\
\hline PVC/L1 & & 2.5 \\
PVC/L2 & lignin & 5 \\
PVC/L3 & & 7.5 \\
PVC/L4 & & 10 \\
\hline PVC/H1 & & 2.5 \\
PVC/H2 & silica-lignin hybrid & 5 \\
PVC/H3 & & 7.5 \\
PVC/H4 & & 10 \\
\hline
\end{tabular}

\subsection{Physicochemical Characteristics of Silica-Lignin Filler}

The dispersive properties of the obtained silica-lignin product were evaluated using Mastersizer $2000(0.2-2000 \mu \mathrm{m})$ and Zetasizer Nano ZS (0.6-6000 nm) instruments (Malvern Instruments Ltd., Worcester, UK), employing laser diffraction and non-invasive back scattering (NIBS) respectively. 
The elemental composition of the fillers was established using a Vario EL Cube instrument (Elementar Analysensysteme GmbH, Hanau, Germany), which is capable of registering the content of carbon, hydrogen, nitrogen and sulfur in samples following high-temperature combustion.

In order to characterize the porous structure parameters of the obtained hybrid material, surface area, total pore volume and average pore size were determined using an ASAP 2020 (Accelerated Surface Area and Porosimetry) instrument (Micromeritics Instrument Co., Norcross, GA, USA). The surface area was determined by the multipoint BET (Brunauer-Emmett-Teller) method using data for adsorption under relative pressure $\left(p / p_{\mathrm{o}}\right)$. The $\mathrm{BJH}$ (Barrett-Joyner-Halenda) algorithm was applied to determine the pore volume and average pore size.

A thermogravimetric (TGA) analyzer (Jupiter STA 449F3, Netzsch, Selb, Germany) was used to investigate the thermal stability of the sample. Measurements were carried out under flowing nitrogen $\left(10 \mathrm{~cm}^{3} / \mathrm{min}\right)$ at a heating rate of $10{ }^{\circ} \mathrm{C} / \mathrm{min}$ over a temperature range of $25-1000{ }^{\circ} \mathrm{C}$, with an initial sample weight of approximately $5 \mathrm{mg}$.

\subsection{Processing Methods and Properties}

\subsubsection{Preparation of PVC Composites}

The main aim of the multi-step method used in the preparation of the PVC composites was to achieve as homogeneous distribution of the fillers in the PVC matrix as possible.

The PVC dry blend and PVC compounds with three types of fillers were processed by melt kneading in the chamber of a Brabender mixer (Brabender GmbH \& Co., Duisburg, Germany) filled with $56 \mathrm{~g}$ of the compound (Plasti-Corder Pl 2200-3 type), with an initial chamber wall temperature of $190{ }^{\circ} \mathrm{C}$, at a rotor speed of $30 \mathrm{rpm}$. The torque of the rotors was recorded as a function of time. The processing of all materials was performed up to the time when the equilibrium state of torque was achieved, i.e., to the point $\mathrm{E}$ on the torque-time curve (see the description of the characteristic points on the torque curve according to $[52,53])$. Both the values of torque at the maximum $\left(M_{\mathrm{X}}\right)$ and the time required to reach the point $\mathrm{X}\left(t_{\mathrm{X}}\right)$ were analyzed. The plastograms for unfilled PVC compound and for the compound with $7.5 \mathrm{wt} \%$ of the three types of filler are presented and discussed (see Figure 1).

In the case of PVC compound with $10 \%$ silica, evidence of degradation during mixing was observed. The progressive degradation causes a further increase in the torque, which took place after the equilibrium state was attained. The torque rise is due to an increase in viscosity which results from the accompanying processes of PVC degradation, mainly cross-linking of polymer chains and autooxidation which results in a branching of the kinetic chain. Moreover, the material discharged from the chamber of the Brabender mixer showed signs of degradation in the form of a yellow-brown color. Further studies using this material were discontinued.

After processing, all PVC materials with and without fillers were ground, and two types of moldings of different thicknesses were processed by compression at a temperature of $180{ }^{\circ} \mathrm{C}$. Samples cut from the moldings were used for the studies of mechanical and thermal properties (tensile properties, Vicat softening temperature) as well as microscopic observations. The processing properties (mass melt flow rate, MFR) and thermal stability (TGA, Congo red thermal stability) were determined with the use of milling. 


\subsubsection{Processing Properties}

Rheological measurements of the PVC dry blend and compounds with the three types of fillers were accomplished using an MFR apparatus of type D4004DE (Dynisco, Morgantown, WV, USA). The measurements were performed at barrel temperature $190{ }^{\circ} \mathrm{C}$ and piston load $400 \mathrm{~N}$, using a capillary die with length $8 \mathrm{~mm}$ and diameter $2 \mathrm{~mm}$.

\subsubsection{Mechanical Properties}

Tensile properties (tensile strength, elongation and Young's modulus) were determined using a Zwick Roell Z010 universal testing machine (Zwick GmbH \& Co. KG, Ulm, Germany), at a strain rate of $20 \mathrm{~mm} / \mathrm{min}$, at room temperature in accordance with the PN-EN ISO 527-1 standard using specimens of type 1BB, $2 \mathrm{~mm}$ in thickness. For each PVC material, 10 specimens were subjected to the tensile procedure and to the impact test.

\subsubsection{Thermal Properties}

Thermogravimetric analysis and the Congo red test were used to investigate the thermal stability of the samples. The TGA measurements of all samples were performed using a Jupiter STA 449F3 thermogravimetric analyzer (Netzsch, Selb, Germany) at a scanning rate of $10{ }^{\circ} \mathrm{C} / \mathrm{min}$ under nitrogen atmosphere in the temperature range $25-900{ }^{\circ} \mathrm{C}$.

Congo red thermal stability was determined at $200{ }^{\circ} \mathrm{C}$ in accordance with the PN-EN ISO 306:2006 standard. Tests of Vicat softening temperature were performed in accordance with PN-EN ISO 306, using $10 \mathrm{~mm} \times 10 \mathrm{~mm} \times 4 \mathrm{~mm}$ specimens. The measurements for each type of sample were carried out three times, in accordance with the requirements of the standard.

\subsubsection{Structure Assessment}

In order to obtain information on the structure of PVC composites and the homogeneity of distribution of filler particles in the PVC matrix, observations were made using optical and electron microscopy. The structure of the processed PVC composite samples was observed by optical microscopy using the Nikon Eclipse E400, Tokyo, Japan) in reflection mode at a magnification of $4 \times$ (compressed films of $0.08 \mathrm{~mm}$ thickness), and by scanning electron microscopy (Zeiss EVO40, Jena, Germany). The samples were broken in liquid nitrogen and, before being placed in the chamber of the microscope, samples were coated with Au for a time of 5 s using a Balzers PV205P coater (Oerlikon Balzers Coating SA, Brügg, Switzerland).

\section{Results and Discussion}

\subsection{Characteristics of Silica-Lignin Filler}

The novel silica-lignin filler was obtained using a mechanical method [51]. The eco-friendly silica-lignin hybrid material was analyzed to determine its dispersive and morphological properties. Results obtained using a Zetasizer Nano ZS analyzer (Malvern Instruments Ltd., Worcester, UK) show 
that the product has particles with sizes in the ranges 79-122 nm and 1720-5560 nm, the maximum contribution coming from particles of size $2670 \mathrm{~nm}$. The heterogeneous structure of the system is confirmed by the results obtained using the Mastersizer 2000 apparatus (Malvern Instruments Ltd., Worcester, UK). These show that $10 \%$ of the sample volume consists of particles with dimensions smaller than $3.8 \mu \mathrm{m}, 50 \%$ consists of particles smaller than $16.5 \mu \mathrm{m}$, and $90 \%$ of the total volume of the final product consists of particles with sizes up to $30.7 \mu \mathrm{m}$.

The effectiveness of the method of producing the $\mathrm{SiO}_{2}$-kraft lignin product was confirmed by elemental analysis, in which carbon, hydrogen and sulfur contents were determined. Lignin, as a macromolecule containing elements including $\mathrm{C}, \mathrm{H}$ and $\mathrm{S}$ in its structure, causes an increase in the quantities of those elements identified in the resulting $\mathrm{SiO}_{2}$-lignin $(\mathrm{C}=8.02 \%, \mathrm{H}=1.45 \%, \mathrm{~S}=0.70 \%)$.

Basic porous structure parameters were also determined: BET surface area, average pore diameter and total pore volume. The BET surface area value for the silica-lignin hybrid material equals $164 \mathrm{~m}^{2} / \mathrm{g}$, while the total pore volume and average pore size are $0.11 \mathrm{~cm}^{3} / \mathrm{g}$ and $4.6 \mathrm{~nm}$ respectively.

From the point of view of the potential use of the bio-based material as a poly(vinyl chloride) filler, tests of thermal stability are extremely important. The TG graph for the silica-lignin hybrid material, given in [51], reveals three characteristic stages. These are presented in detail in Table 2.

Table 2. Three characteristic stage of weight loss for silica-lignin hybrid material.

\begin{tabular}{cccc}
\hline Stage & Mass loss $(\%)$ & Temperature range $\left({ }^{\circ} \mathbf{C}\right)$ & Cause/reason \\
\hline 1 & 4 & $30-220$ & $\begin{array}{c}\text { Desorption of physically bound water from the } \\
\text { surface of the product. }\end{array}$ \\
2 & 6 & $220-650$ & $\begin{array}{c}\text { Thermal decomposition of lignin } \\
\text { macromolecule. }\end{array}$ \\
3 & 2 & $650-1000$ & $\begin{array}{c}\text { Fragmentation, combined with the degradation } \\
\text { of the compound. }\end{array}$ \\
\hline
\end{tabular}

Combining silica with lignin resulted in a product with very good thermal properties. Here the weight loss over the entire temperature range is only $\sim 12 \%$. This can be ascribed to the fact that the content of silica is four times greater than that of lignin.

\subsection{Processing Properties}

Figure 1 shows plots of torque vs. kneading time for the original PVC and PVC compounds with $7.5 \mathrm{wt} \%$ of silica, lignin and silica-lignin hybrid material, where the first small torque maximum observed on the plastograms of PVC and PVC/L is related to the feeding of the chamber. The shape of all plastograms is characteristic for the processing of rigid PVC compounds and is closely linked to the occurrence of the gelation effect, which takes place depending on the applied shear rate, temperature and PVC composition (Figure 1). This PVC gelation effect may be noted on the plastogram as a maximum of torque, followed by a relatively high constant value in the equilibrium state $[52,53]$.

The torque plot is similar for both materials, i.e., PVC and PVC/L. In this case, a relatively low value of torque was usually observed, whereas the time when the maximum torque occurred was substantially shorter in the case of PVC/L (about 5-6 min). The maximum value of the torque for this mixture is 
comparable to that obtained for the unfilled PVC, and is practically constant and independent of the concentration of filler in the PVC mixture (Figure 2).

For PVC/S and PVC/H composites the maximum of torque, attributed to PVC gelation, attained considerably higher values compared with PVC and PVC/L. Moreover, Figure 2 shows that the maximum value of the torque increases with increasing content of the filler in the PVC compound, particularly in the case of silica.

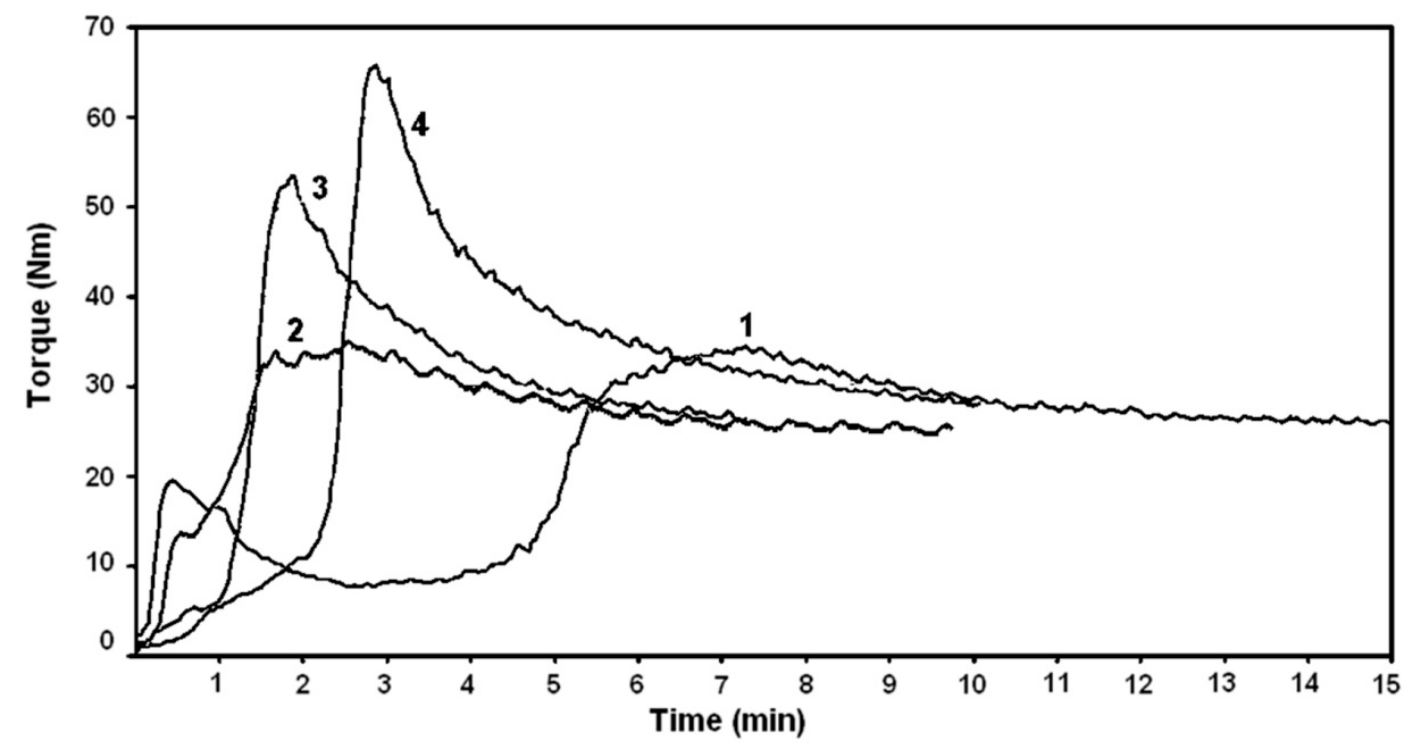

Figure 1. Torque vs. time of kneading for: 1, PVC, and PVC composites; 2, PVC/L; 3, PVC/H; 4, PVC/S.

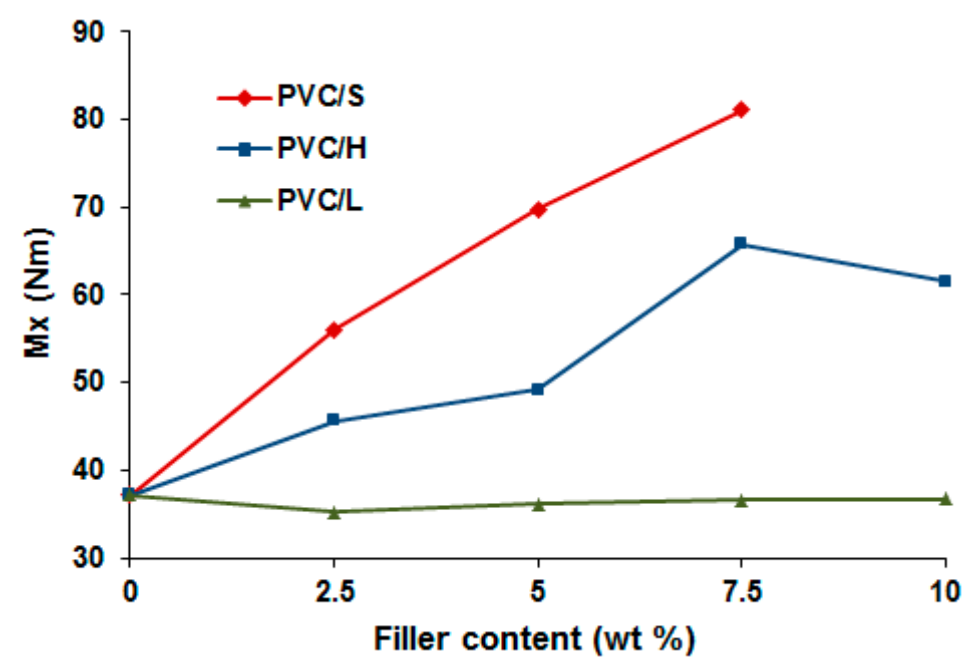

Figure 2. Maximum value of torque $\left(M_{\mathrm{X}}\right)$ for $\mathrm{PVC}$ and $\mathrm{PVC}$ composites as a function of filler content.

The time position of this maximum value, however, is shorter relative to the value for PVC (Figure 3). A noticeable decrease in $t_{\mathrm{X}}$ is already observed for a $2.5 \mathrm{wt} \%$ addition of filler, independent of its type. A further increase of filler concentration does not lead to significant change in the time of gelation. Analysis of these data shows that all of the studied fillers significantly shorten the gelation time, which is important from an economic standpoint. The most efficient modifier appears to be the silica-lignin 
hybrid material, because the gelation time of $\mathrm{PVC} / \mathrm{H}$ composites is the shortest. The gelation of $\mathrm{PVC}$ is closely related to the disintegration of primary grains into smaller elements, i.e., agglomerates of primary particles, resulting from the action of shear stresses. The addition of fillers causes an increase in the shear stresses, which results in the grinding of grains and consequently earlier gelation in comparison with the unfilled PVC compound. The addition of silica or silica-lignin hybrid filler causes a substantial increase in torque, which may be associated with a significant increase in the mechanical charging of machines in real processing conditions.

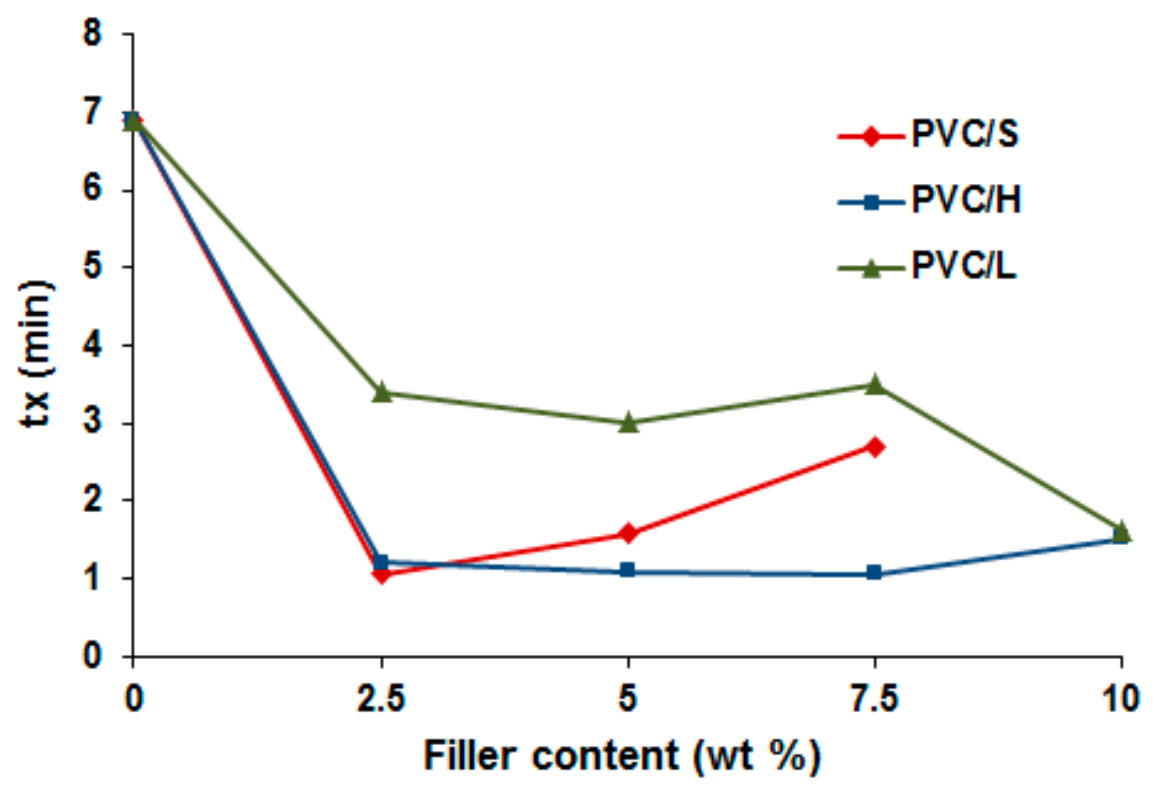

Figure 3. Time to reach the maximum value of torque $\left(t_{\mathrm{X}}\right)$ for PVC and PVC composites as a function of filler content.

Our results agreed well with other reports as regards the influence of particles of $\mathrm{SiO}_{2}$ as well as nanocarbon black on the fusion behavior of PVC composites [54,55]. The increased speed of fusion and the increase in the fusion torque of the PVC composites filled with $\mathrm{SiO}_{2}$ and nanocarbon black were explained by the increase in friction in the system and the increase in the transfer of heat and shear through the PVC grains. The results are in accordance with our results previously described for composites of PVC with wood flour (WF) [56]. It was ascertained that during PVC fusion, stronger self-heating effects occur in the WF-filled PVC compounds, compared with pure PVC. This effect stems from the large amount of heat released as a result of friction of wood particles against wood particles and/or PVC grains, wood particles and/or PVC grains against the wall surface of the chamber, and PVC grains against PVC grains.

The effect of promote of friction in the case of the lignin particles is probably smaller than in the other two cases; the lignin introduced into the PVC matrix probably acts as a lubricant of PVC grains.

The MFR values of all PVC composites are lower than for unfilled PVC, and they decrease with an increase in the filler content in the PVC compound (Figure 4). This indicates that the use of the fillers in PVC has an unfavorable effect on the melt viscosity. In the case of PVC/silica composites it was possible to determine MFR values for samples containing up to $2.5 \mathrm{wt} \%$ of filler. The PVC composite 
with 5 wt $\%$ of silica gradually degrades during heating in the cylinder over the time required to bring the material to a melting state.

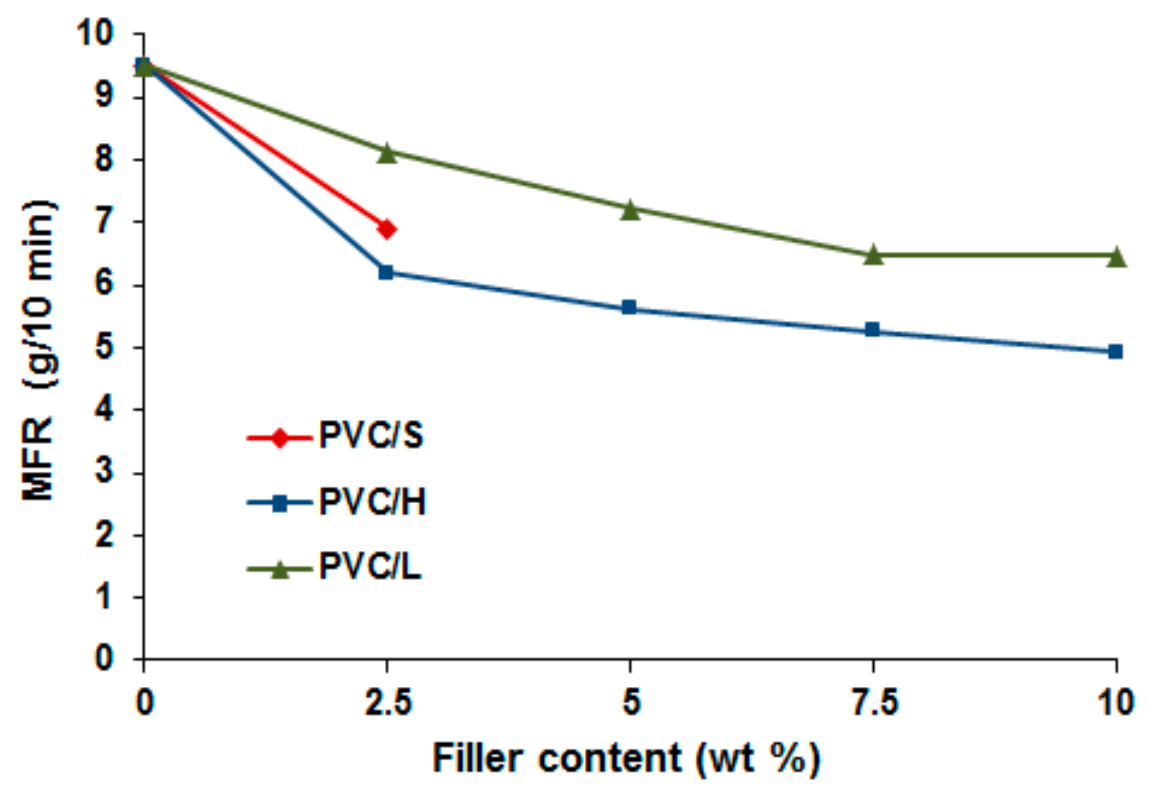

Figure 4. MFR of PVC and PVC composites vs. filler content.

\subsection{Thermal Properties}

Determination of the thermal stability of PVC is very important because of its thermal and shear sensitivity during processing. This parameter provides some valuable information relating to processing conditions, including in the case where the PVC serves as the matrix of composites with natural fillers.

The thermal stability of PVC and its composites was investigated by TG analysis. For example, the thermograms recorded in the temperature range $25-900{ }^{\circ} \mathrm{C}$, for PVC and for composites with a PVC matrix containing $7.5 \mathrm{wt} \%$ of the three respective types of fillers, are presented in Figure 5. All TG curves indicate two major stages of weight loss. The degradation trend of PVC composite is similar to that of unfilled PVC. The first stage of the process occurs in the temperature range $220-260{ }^{\circ} \mathrm{C}$ and is related to the PVC dehydrochlorination sequential reaction and formation of conjugated polyene sequences. The second stage, occurring in a higher temperature range, corresponds to thermal cracking of the carbonaceous conjugated polyene sequences. The two peaks in the TG thermograms are indicative of the maximum rate of weight loss, corresponding to the temperatures with the most rapid degradation during each stage [57-62]. The main component of the residue of the sample PVC is in carbonaceous form (char) due to the fact that the TGA tests were performed in the nitrogen atmosphere. In the case of the PVC filled with silica, an additional residue of inorganic origin is observed due to significant thermal stability of silicon dioxide (only dehydration effects at 120 and $500{ }^{\circ} \mathrm{C}$ are observed). The residue of PVC/lignin sample is higher compared to the PVC due to the increase of total amount of carbon (charring materials, such as lignin, leave fractions of the original carbon content as carbonaceous residue). 


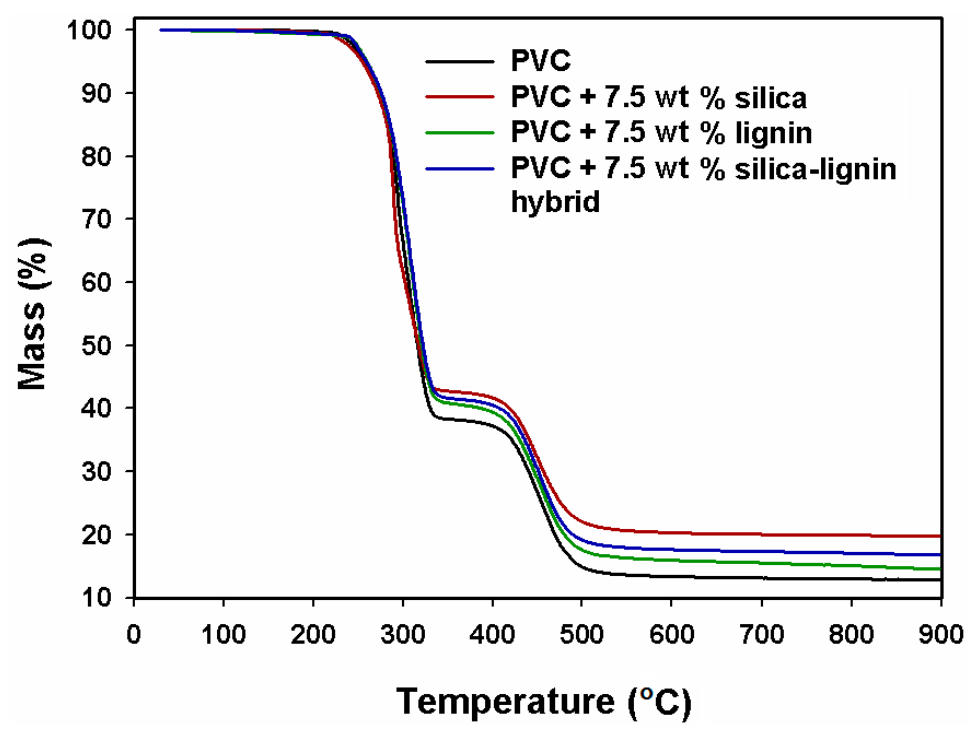

Figure 5. TG curves of PVC and PVC-based composites with 7.5 wt $\%$ filler content.

The thermograms for samples of PVC composites containing various quantities of the silica-lignin filler, over the temperature range $220-340{ }^{\circ} \mathrm{C}$, are shown in Figure 6.

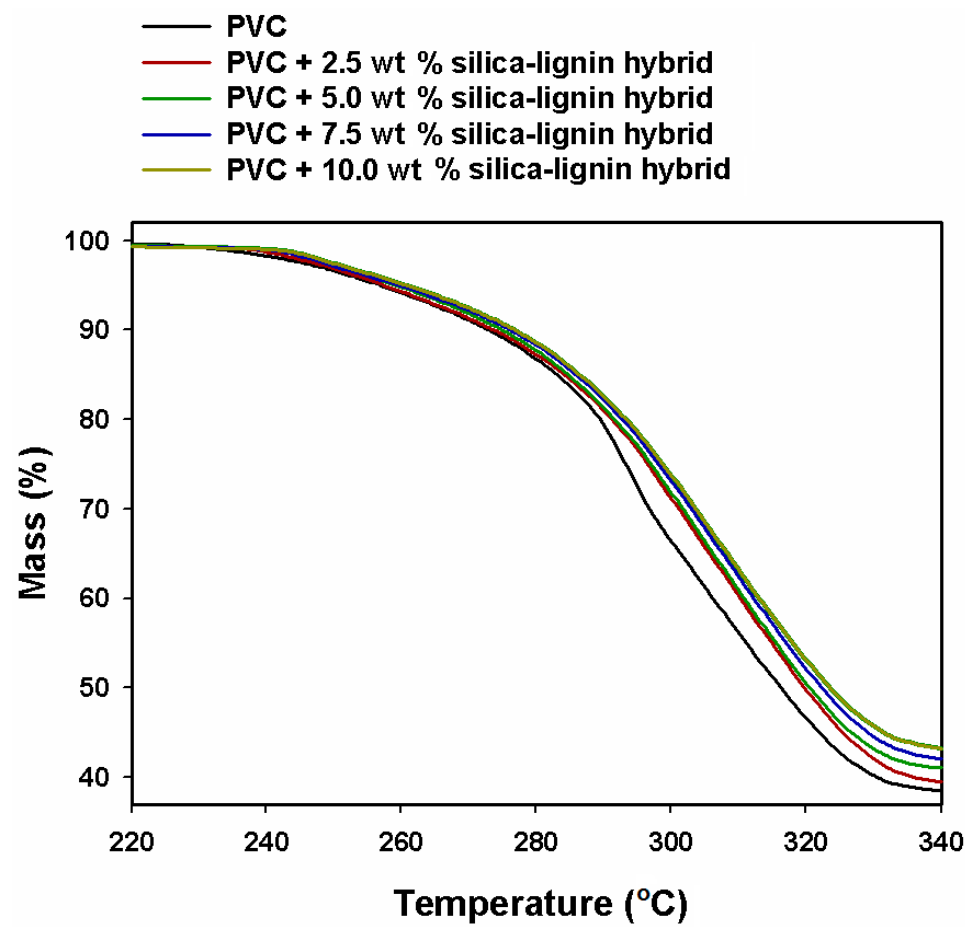

Figure 6. TG curves of PVC and PVC-silica-lignin composites with various filler contents.

Although the degradation of $\mathrm{PVC}$ and of $\mathrm{PVC} / \mathrm{H}$ composite follows similar trends, there are differences in the form of the TG curves, especially in the range $280-340{ }^{\circ} \mathrm{C}$. It is particularly evident that with increasing concentration of the hybrid silica-lignin particles in the PVC matrix, the temperature of $50 \%$ weight loss is shifted toward higher values. The temperatures of $1 \%, 5 \%$ and $50 \%$ weight loss of all PVC samples are summarized in Table 3. 
Table 3. The thermal stability properties of the tested materials.

\begin{tabular}{cccc}
\hline \multirow{2}{*}{ Sample } & \multicolumn{3}{c}{ Temperature value of weight loss $\left({ }^{\circ} \mathbf{C}\right)$} \\
\cline { 2 - 4 } & $\mathbf{1 \%}$ & $\mathbf{5 \%}$ & $\mathbf{5 0 \%}$ \\
\hline PVC & 233 & 257 & 316 \\
\hline PVC/S1 & 228 & 255 & 317 \\
PVC/S2 & 225 & 256 & 316 \\
PVC/S3 & 224 & 255 & 317 \\
\hline PVC/L1 & 237 & 257 & 320 \\
PVC/L2 & 239 & 259 & 319 \\
PVC/L3 & 236 & 260 & 321 \\
PVC/L4 & 237 & 260 & 322 \\
\hline PVC/H1 & 238 & 257 & 319 \\
PVC/H2 & 241 & 259 & 321 \\
PVC/H3 & 240 & 260 & 322 \\
PVC/H4 & 240 & 261 & 323 \\
\hline
\end{tabular}

These data show that the temperatures of $1 \%, 5 \%$ and $50 \%$ weight loss, associated with progressive degradation, are higher for composites containing lignin and the silica-lignin hybrid filler than for unfilled PVC. Modification of PVC with natural filler in the form of lignin, including when combined with silica, leads to an increase in the thermal stability of the polymer, which increases slightly with increasing content of these fillers in the matrix. Comparing silica-lignin filler with pure lignin, the initial degradation process of $\mathrm{PVC} / \mathrm{H}$ occurs at a somewhat higher temperature than in the case of $\mathrm{PVC} / \mathrm{L}$ (by about $2-3{ }^{\circ} \mathrm{C}$ ). The values of the temperature of $50 \%$ weight loss are approximately the same for $\mathrm{PVC} / \mathrm{L}$ and $\mathrm{PVC} / \mathrm{H}$. The hybrid material seems to be a more effective filler for PVC in terms of its thermal stability. Simultaneously, a significant decrease in thermal stability was observed as the silica content in the PVC matrix increased, especially in the initial stage of PVC decomposition. This observation is in accordance with [63], where TGA results showed that $\mathrm{SiO}_{2}$ particles lowered the first thermal degradation temperature (T-onset) of PVC by initiating dehydrochlorination of PVC at lower temperatures. Moreover, the thermal degradation onset temperature was shifted to lower temperatures with decreasing $\mathrm{SiO}_{2}$ particle size [54]. However, the literature describes the positive impact of silica produced by the sol-gel method on the thermal stability of PVC/silica hybrids. These hybrids were prepared from a solution, and were therefore not subjected to the action of heat and shear stresses which may cause mechano-thermal degradation of the material [8].

The results of Congo red thermal stability tests confirm these observations. The results indicate that both lignin and silica-lignin hybrid filler cause an increase in thermal stability compared with the pure PVC, over the studied range of concentrations of the filler (Figure 7). A concentration of only 2.5 wt \% of both types of filler significantly improves the thermal stability of PVC composites; a further increase in the filler content causes the time of initial degradation to increase by more than 2.5 times. It should also be noted that the PVC dry blend used as the matrix of the composites offers good thermal stability, ensuring a high degree of effectiveness of the applied thermal stabilizer. The addition of silica causes significant deterioration in the thermal stability of the PVC, already observed during processing of the 
PVC compound with a filler content of $10 \mathrm{wt} \%$, and in MFR measurements in the case of gelated PVC compound with 5 wt \% silica content.

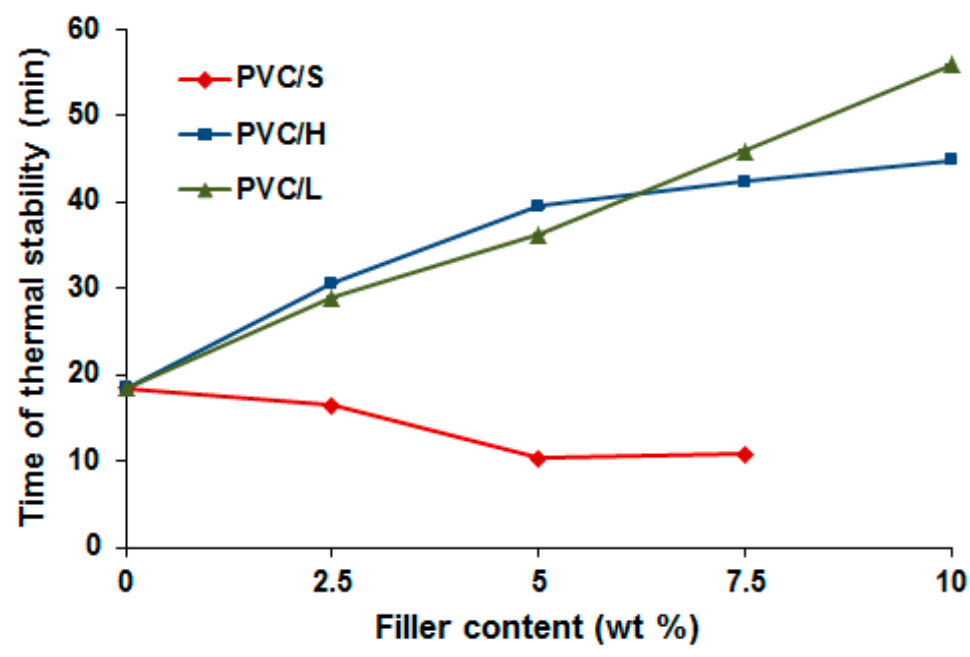

Figure 7. Time of thermal stability of PVC and PVC-based composites vs. filler content (PVC/S, PVC/L and PVC/H).

In summary, both lignin and silica-lignin hybrid fillers have a positive impact on the thermal properties of poly(vinyl chloride). Due to their positive influence on stability, both can be used successfully in the processing of PVC composites.

The thermal stability of silica-lignin hybrid composite depends mainly on the resistance to higher temperatures of the raw materials from which it is made. Silica has high thermal stability; up to $1000{ }^{\circ} \mathrm{C}$ it loses about $5 \%$ of its mass. In the case of lignin the thermal decomposition processes occur rapidly in a temperature range from $200{ }^{\circ} \mathrm{C}$ to $600{ }^{\circ} \mathrm{C}$. Research on hybrid composites has shown that a two-component silicalignin material mix ensures a heat resistance temperature of about $250{ }^{\circ} \mathrm{C}$ [51]. However, the introduction of these fillers into PVC causes changes in the thermal stability of the composites, independently of their original thermal properties.

The deterioration of the thermal stability of PVC/S composites may be related to mechano-thermal degradation of PVC macromolecules through processing. During kneading in the Brabender chamber there is additional intense friction related to the presence of silica particles, which are hard and rigid and do not deform as a result of heat. This causes a supplementary effect of self-heating of the processed material, which results in an increase in the real temperature of the processed mixture, which is higher than the adjusted temperature of the chamber, as described in our earlier work for rigid PVC compounds with wood flour [56]. Despite the addition of the thermal stabilizer, shear stresses and heat during melt processing cause the initiation of PVC degradation. This observation confirms those made during the MFR measurements, where the PVC/S with 5 wt \% of filler content decomposes during the test. In this material, the degradation process has already been initiated during processing. The similar effect of the decrease of thermal stability related to the incorporation of the silica aerogel was described for PVC plastisol, which was used for a preparation of PVC-coated polyester woven fabric. According to Jabbari et al., one of the reasons for the slight decrease of onset decomposition temperature might 
originate from the possibility that aerogel's oxygen catalyses the decomposition reactions [64]. Oxygen plays a catalytic role during the PVC degradation possibly by increasing the number of initiation sites.

The introduction of lignin and silica-lignin hybrid filler into PVC improves the thermal stability of the composite, which is probably due to the lubricating action of lignin. Such an effect is confirmed by the results of processing testing, i.e., a smaller maximum of torque recorded in comparison with the $M_{\mathrm{X}}$ of unfilled PVC. Another explanation of this effect is proposed in [65]. The authors concluded that the methoxy groups in phenolic rings in lignin are the methyl source of chloromethane formation, and that this reaction consumes most of the $\mathrm{HCl}$ evolved from the PVC.

Figure 8 shows the softening temperature of PVC as a function of the filler content in PVC composites. The addition of $7.5 \mathrm{wt} \%$ of silica and hybrid filler visibly increases this temperature in comparison with the origin PVC sample, by as much as $10{ }^{\circ} \mathrm{C}$ in the case of $\mathrm{PVC} / \mathrm{H}$ and $14{ }^{\circ} \mathrm{C}$ for the $\mathrm{PVC} / \mathrm{S}$ sample. The effect of increase in the softening temperature is extremely important from the point of view of applications of PVC composite products, as it makes it possible to extend the range of applications of PVC composites with silica-lignin filler at increased temperature. Although PVC composites containing 7.5 wt \% silica also exhibit increased softening temperature (in comparison with neat PVC), due to the adverse impact of this filler on the thermal stability of the composition and also on processing properties (high torque) it can be suggested that silica-lignin hybrid fillers are a very promising material precisely for application in polymer modification.

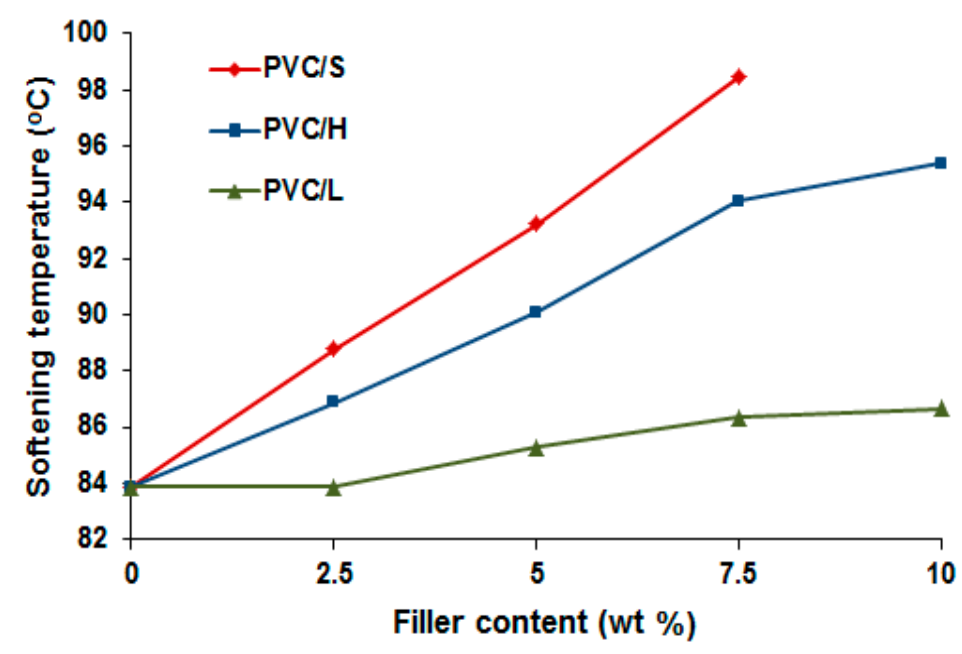

Figure 8. Softening temperature of $\mathrm{PVC}$ and $\mathrm{PVC}$-based composites vs. filler content (PVC/S, PVC/L and PVC/H).

\subsection{Mechanical Properties}

The mechanical stress-strain curves of PVC composites with $7.5 \mathrm{wt} \%$ of silica and lignin separately, as well as silica-lignin fillers, are presented in Figure 9a and for composites with different content of hybrid fillers in Figure 9b. Depending on the filler type and content, for all investigated samples changes in the stress-strain behavior may be observed. 

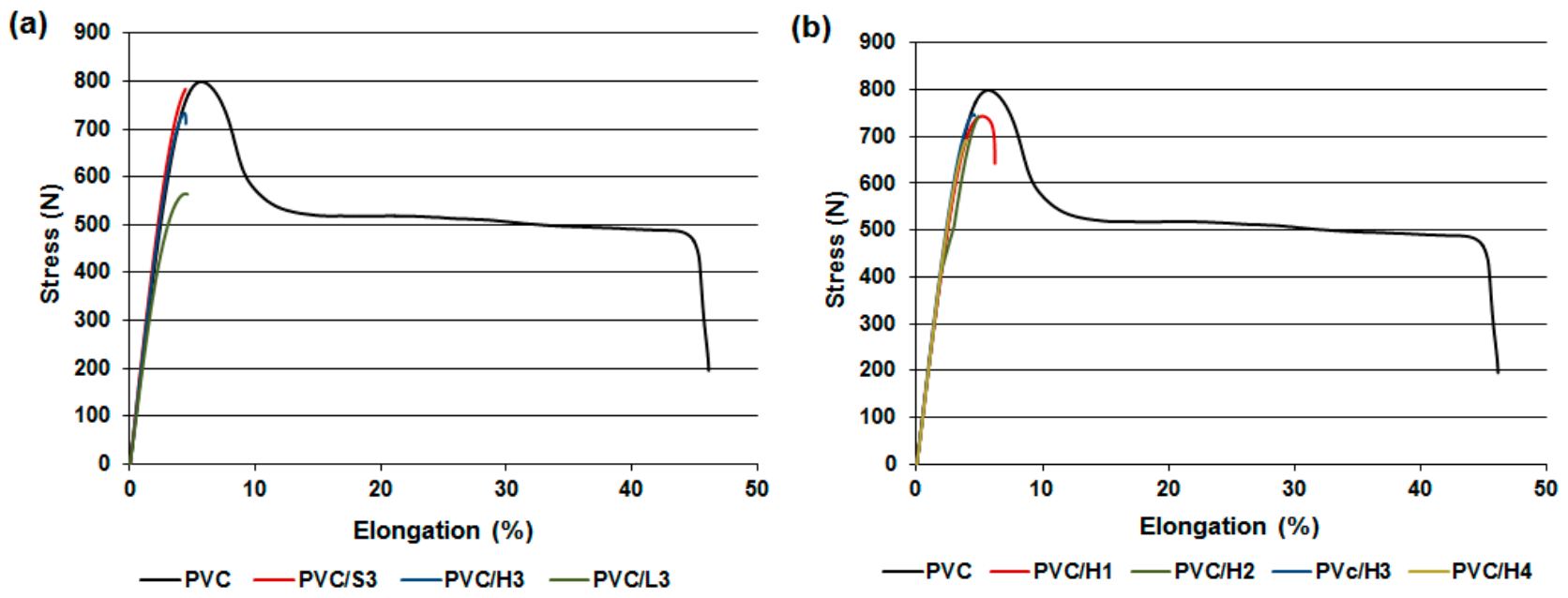

Figure 9. Mechanical stress-strain curves of PVC composites with $7.5 \mathrm{wt} \%$ content of silica and lignin individually, as well as silica-lignin fillers (a) and for composites with different content of hybrid fillers (b).

In the case of neat PVC, a ductile-type fracture accompanied by a significant plastic deformation was noted. A clear Yield point appears on the curve where its value represents the tensile strength $\left(\delta_{\mathrm{Y}}=\delta_{\mathrm{M}}\right)$. Similar stress-strain behaviors are observed for PVC/S and PVC/H composites containing $2.5 \mathrm{wt} \%$ of filler. In the case of higher filler concentration, a transformation from ductile to brittle-like fracture was observed, and consequently the Yield point disappeared. On the contrary, in the case of PVC/L samples firstly the brittle-like fracture takes place by the lignin in PVC matrix concentration equal or higher than $10 \mathrm{wt} \%$.

The values of mechanical properties (Table 4) show that the incorporation of silica, lignin and silica-lignin hybrid material into PVC leads to a slight increase in Young's modulus relative to unfilled PVC. The silica brings about the most effective improvement in Young's modulus, with increasing silica content. In the case of $\mathrm{PVC} / \mathrm{L}$ and $\mathrm{PVC} / \mathrm{H}$ composites, no clear dependence of the modulus on the filler content is observed. The results for tensile strength indicate that the addition of small amounts of silica (up to $5 \mathrm{wt} \%$ ) results in an increase in strength compared with the unfilled PVC. PVC/H composite has a tensile strength comparable to that of the unmodified PVC. The value of $\delta$ is lowest for the material containing $10 \mathrm{wt} \%$ lignin/silica filler, but is still sufficiently high for many applications such as construction material. The addition of lignin to the PVC compound results in a drop of tensile strength. In all cases, the addition of fillers causes a radical reduction of the elongation at break, regardless their type and concentration. The introduction of $2.5 \mathrm{wt} \%$ of filler results in a decrease in elongation to about $7 \%$, while the relative elongation of unfilled PVC is $50 \%$. Further increase of filler content, above $2.5 \mathrm{wt} \%$, does not have a significant impact on the decrease of elongation at break. As regards the mechanical properties of PVC composites, the most favorable effect may be observed in case of application of silica and silica-lignin filler in the PVC matrix. However, considering the other thermal and processing properties of PVC/S composites, application of the silica-lignin hybrid material appears to be more advantageous. 
Table 4. Mechanical properties of the tested materials.

\begin{tabular}{lcccc}
\hline Sample & Young modulus $\boldsymbol{E}(\mathbf{M P a})$ & Yield point $\delta_{\mathbf{Y}}(\mathbf{M P a})$ & Tensile strength $\delta_{\mathbf{M}}(\mathbf{M P a})$ & Elongation at break $(\%)$ \\
\hline PVC & $1,530 \pm 62.2$ & $57.1 \pm 1.2$ & $57.1 \pm 1.2$ & $52.4 \pm 8.3$ \\
PVC/S1 & $1,650 \pm 33.4$ & $59.3 \pm 1.5$ & $59.3 \pm 1.5$ & $7.2 \pm 1.1$ \\
PVC/S2 & $1,710 \pm 48.1$ & - & $60.2 \pm 2.1$ & $5.4 \pm 1.2$ \\
PVC/S3 & $1,720 \pm 81.6$ & - & $57.6 \pm 1.8$ & $4.3 \pm 0.5$ \\
PVC/L1 & $1,600 \pm 55.5$ & $53.5 \pm 0.9$ & $53.5 \pm 0.9$ & $8.8 \pm 1.8$ \\
PVC/L2 & $1,580 \pm 38.7$ & $50.3 \pm 0.7$ & $50.3 \pm 0.7$ & $6.5 \pm 0.9$ \\
PVC/L3 & $1,570 \pm 113.4$ & $44.7 \pm 3.7$ & $44.7 \pm 3.7$ & $5.3 \pm 1.2$ \\
PVC/L4 & $1,590 \pm 135.3$ & - & $39.5 \pm 2.3$ & $3.9 \pm 0.6$ \\
PVC/H1 & $1,630 \pm 44.1$ & $57.1 \pm 1.3$ & $57.1 \pm 1.3$ & $7.8 \pm 1.7$ \\
PVC/H2 & $1,690 \pm 56.8$ & - & $54.8 \pm 1.3$ & $4.8 \pm 0.9$ \\
PVC/H3 & $1,670 \pm 45.3$ & - & $55.9 \pm 1.1$ & $4.5 \pm 0.3$ \\
PVC/H4 & $1,630 \pm 117.0$ & - & $50.9 \pm 2.4$ & $3.7 \pm 0.3$ \\
\hline
\end{tabular}

\subsection{Microscopic Observations}

It is well-known that the structure of composite materials determines their properties, especially such structural factors as bonding strength on the interface between the dispersed phase and matrix, shape of dispersed phase inclusions, and homogeneity of distribution of filler particles in the polymer matrix.

Figure 10 shows images from the optical microscope of PVC/silica and PVC/lignin systems. In Figure 10a well dispersed silica particles in the matrix polymer can be seen, showing a reduced tendency to aggregation. On the other hand, PVC/lignin system is characterized with significantly worse homogeneity (Figure 10b). The particles have a relatively high tendency to agglomerate and are arranged non-uniformly.
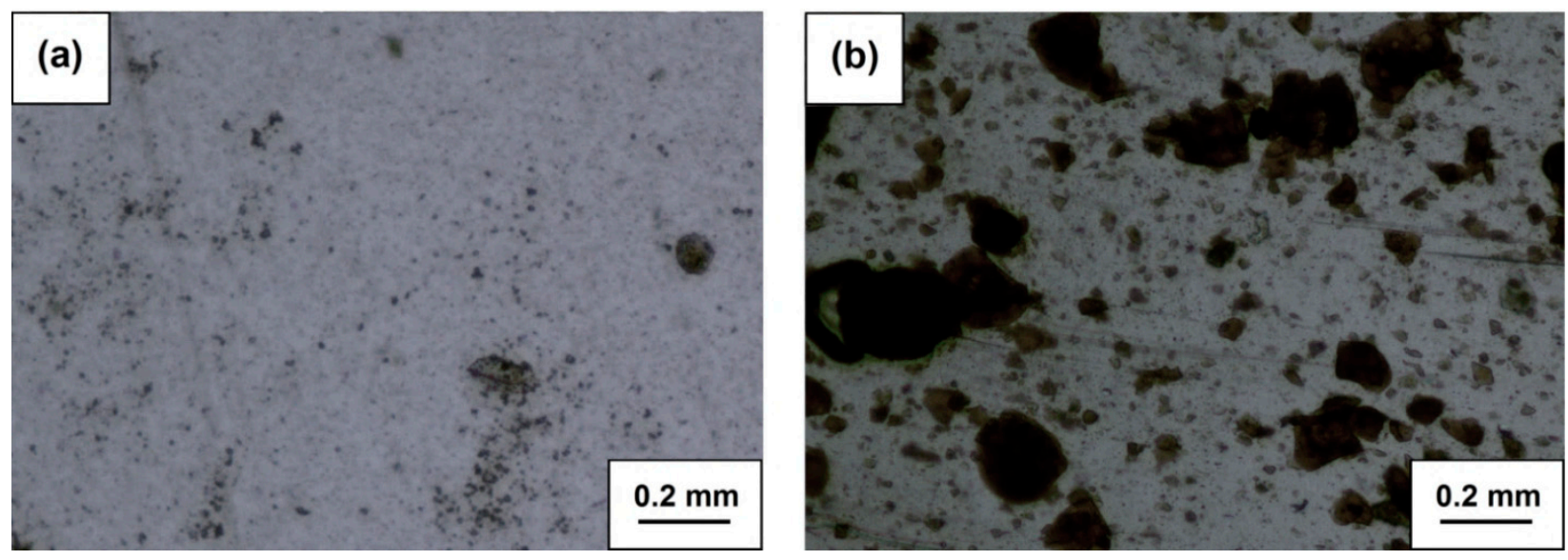

Figure 10. Optical microscopy images of PVC/silica (a) and PVC/lignin (b) composites with filler content in both materials equal to $7.5 \mathrm{wt} \%$.

Observations of the $\mathrm{PVC} / \mathrm{H}$ structure performed using optical microscopy indicated that filling with up to $10 \mathrm{wt} \%$ of silica-lignin particles does not cause the occurrence of particle aggregates. Furthermore, from Figure 11 it can be seen that the hybrid filler particles are dispersed uniformly in the PVC matrix. The silica-lignin particles have an irregular shape; most of the particles have a size of $50 \mu \mathrm{m}$, although there are also some larger than $100 \mu \mathrm{m}$ present. 

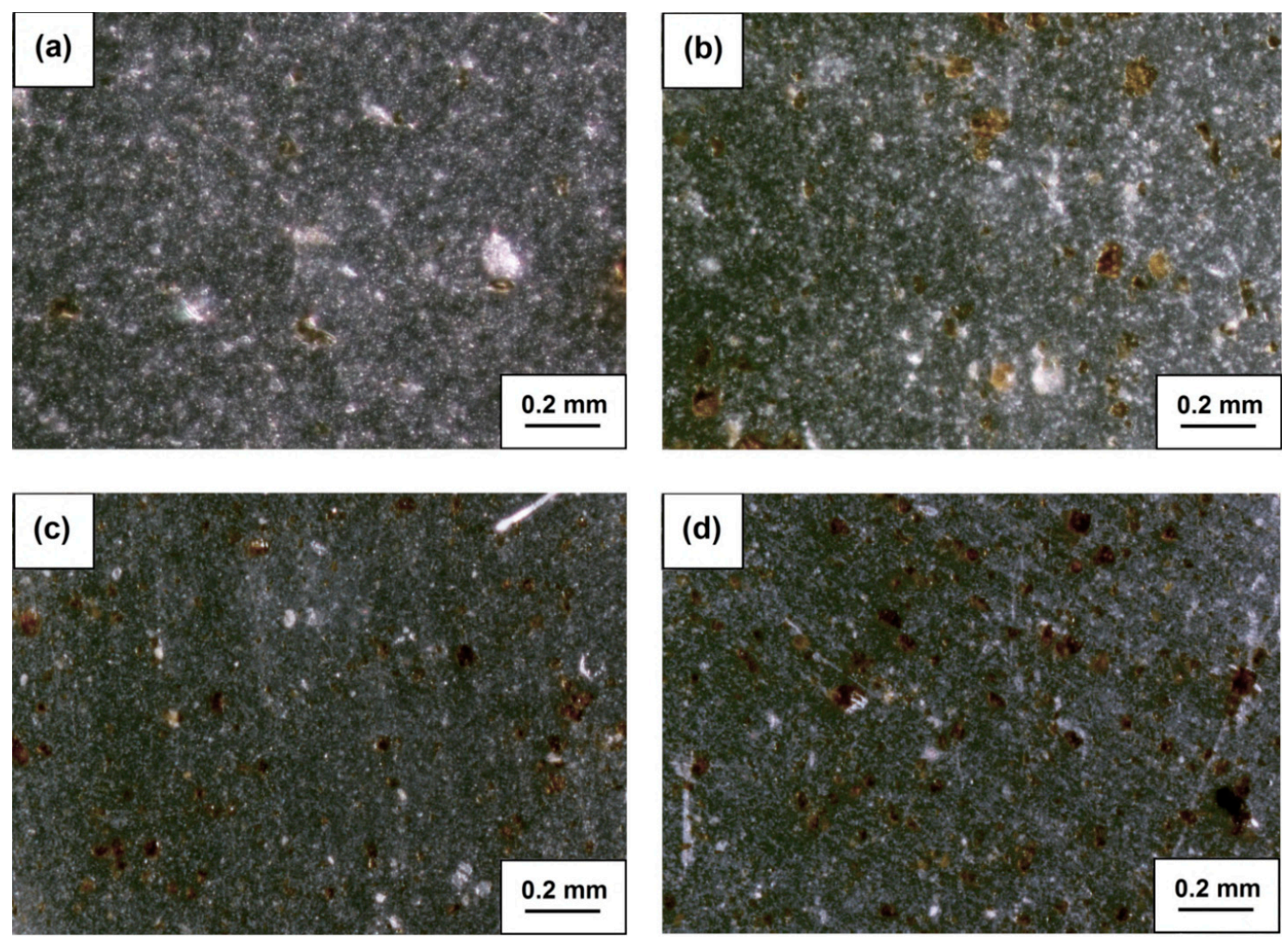

Figure 11. Optical microscopy images of PVC/silica-lignin composites with different filler content: (a) $2.5 \mathrm{wt} \%$; (b) $5 \mathrm{wt} \%$; (c) $7.5 \mathrm{wt} \%$; (d) $10 \mathrm{wt} \%$.

In the SEM image (Figure 12) of a PVC/H sample with $7.5 \mathrm{wt} \%$ of silica-lignin, a layered structure characteristic of gelated PVC can be identified, where the individual particles of the silica-lignin hybrid filler are visible. On the basis of SEM observation at high magnification, it seems likely that good adhesion took place between the PVC matrix and the silica-lignin dispersed phase.
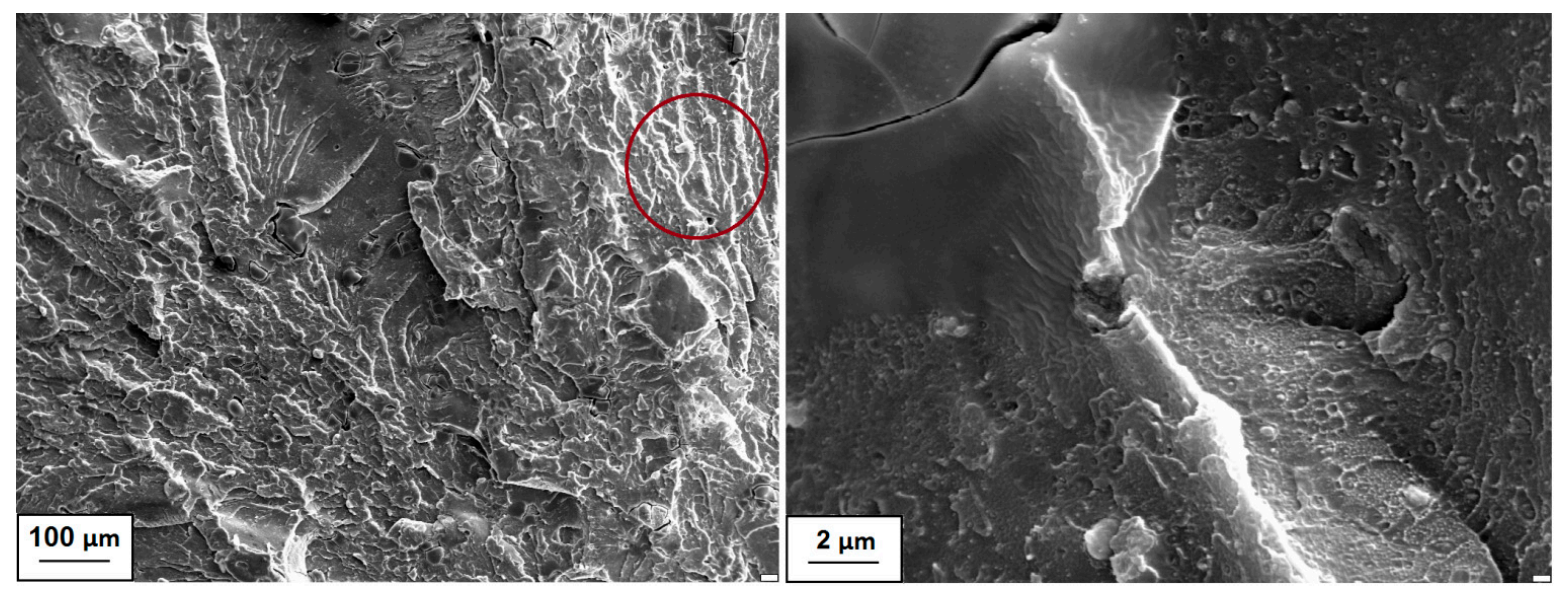

Figure 12. SEM images of PVC/silica-lignin composite with 7.5 wt $\%$ filler content (area marked with a circle shows the PVC layered structure). 


\section{Conclusions}

It is possible to obtain a composite with a PVC matrix containing up to $10 \mathrm{wt} \%$ of silica-lignin filler by means of the melt processing method used. The use of a hybrid filler with the composition proposed in this work promotes the uniformity of the resulting PVC composite structure, as confirmed by microscopic observations. The kneading-induced gelation of the PVC matrix in the composites with silica-lignin filler takes place in a shorter time than that required for the neat PVC, but the addition of hybrid filler results in a significant increase in torque during kneading, which may result in an increase in the mechanical charging of processing units in technological conditions. PVC/silica-lignin composites exhibit a higher Young's modulus than neat PVC, and without a notable reduction in tensile strength. Silica-lignin hybrid fillers have a positive effect on the Vicat softening temperature, which is important from the perspective of applications, and on the thermal stability of the PVC composites. This feature of the material allows the compound to be safely processed without risk of thermal decomposition of the PVC. This is particularly relevant given the possibility of producing composite materials by conventional processing methods, e.g., extrusion. For the user of products manufactured with use of the proposed materials, there are very important properties associated with the Vicat softening temperature. It would be advantageous to conduct further research on the optimization of silica-lignin hybrid filler.

\section{Acknowledgments}

The study was financed with funds from the Polish National Centre of Science according to decision No. DEC-2013/09/B/ST8/00159.

\section{Author Contributions}

Łukasz Klapiszewski-Planning studies. Preparation of silica-lignin hybrid filler. Analysis of physicochemical and dispersive-morphological properties of the material obtained. Results development. Franciszek Pawlak-Preparation of PVC/silica-lignin composites. Results development. Jolanta Tomaszewska-Planning studies. Analysis of processing, thermal and mechanical properties of PVC/silica-lignin composites. Elaboration of the obtained results. Teofil Jesionowski-Coordination of all tasks in the paper. Planning studies. Results development.

\section{Conflicts of Interest}

The authors declare no conflict of interest.

\section{References}

1. Yang, S.Y.; Liu, L.; Jia, Z.X.; Fu, W.W.; Jia, D.M.; Luo, Y.F. Study on the structure-properties relationship of natural rubber/SiO${ }_{2}$ composites modified by a novel multi-functional rubber agent. eXPRESS Polym. Lett. 2014, 8, 425-435. [CrossRef]

2. Estevez, M.; Rodriguez, R.J.; Vargas, S.; Guerra, J.A.; Brostow, W.; Lobland, H.E.H. Scratch and abrasion properties of polyurethane-based micro- and nano-hybrids obturation materials. J. Nanosci. Nanotechnol. 2013, 13, 4446-4455. [CrossRef] [PubMed] 
3. Bolbukh, Y.; Kuzema, P.; Tertykh, V.A.; Laguta, I. Thermal degradation of polyethylene containing antioxidant and hydrophilic/hydrophobic silica. J. Therm. Anal. Calorim. 2008, 94, 727-736. [CrossRef]

4. Zhou, T.H.; Ruan, W.H.; Mai, Y.L.; Rong, M.Z.; Zhang, M.Q. Performance improvement of nano-silica/polypropylene composites through in-situ cross-linking approach. Compos. Sci. Technol. 2008, 68, 2858-2863. [CrossRef]

5. Zhang, W.H.; Fan, X.D.; Tian, W.; Fan, W.W. Polystyrene/nano-SiO $\mathrm{O}_{2}$ composite microspheres fabricated by Pickering emulsion polymerization: Preparation, mechanisms and thermal properties. eXPRESS Polym. Lett. 2012, 6, 532-542. [CrossRef]

6. Al-Sagheer, F.A.; Ahmad, Z. PVC-silica hybrids: Effect of sol-gel conditions on the morphology of silica particles and thermal mechanical properties of the hybrids. J. Sol-Gel Sci. Technol. 2012, 61, 229-235. [CrossRef]

7. Bolbukh, Y.; Tertykh, V.A.; Klonos, P.; Pissis, P. DSC study of polyhydroxyethyl-methacrylate filled with modified silicas. J. Therm. Anal. Calorim. 2012, 108, 1111-1119. [CrossRef]

8. Brostow, W.; Datashvili, T.; Hackenberg, K.P. Synthesis and characterization of poly(methyl acrylate) $+\mathrm{SiO}_{2}$ hybrids. E-Polymers 2008, $8,1-13$. [CrossRef]

9. Jesionowski, T.; Bula, K.; Janiszewski, J.; Jurga, J. The influence of filler modification on its aggregation and dispersion behaviour in silica PBT composite. Compos. Interface 2003, 10, 225-242. [CrossRef]

10. Maciejewska, M.; Zaborski, M. Effect of ionic liquids on the dispersion of zinc oxide and silica nanoparticles, vulcanization behavior and properties of NBR composites. eXPRESS Polym. Lett. 2014, 8, 932-940. [CrossRef]

11. Pietrasik, J.; Gaca, M.; Zaborski, M.; Okrasa, L.; Boiteux, G.; Gain, O. Studies of molecular dynamics of carboxylated acrylonitrile-butadiene rubber composites containing in situ synthesized silica particles. Eur. Polym. J. 2009, 45, 3317-3325. [CrossRef]

12. Brostow, W.; Chonkaew, W.; Datashvili, T.; Menard, K.P. Tribological properties of epoxy+silica hybrid materials. J. Nanosci. Nanotechnol. 2009, 9, 1916-1922. [CrossRef] [PubMed]

13. Faruk, O.; Błędzki, A.K.; Fink, H.P.; Sain, M. Progress report on natural fiber reinforced composites. Macromol. Mater. Eng. 2014, 229, 9-26. [CrossRef]

14. Tomaszewska, J.; Zajchowski, S. Study on the mechanical properties and structure of the compounds of PE/PVC recyclates filled with wood flour. Polimery 2013, 58, 106-113. [CrossRef]

15. Jiang, H.; Kamdem, D.P. Development of poly(vinyl chloride)/wood composites. A literature review. J. Vinyl Addit. Technol. 2004, 10, 59-69. [CrossRef]

16. Khan, R.A.; Sharmin, N.; Khan, M.A.; Das, A.K.; Dey, K.; Saha, S.; Islam, T.; Islam, R.; Nigar, F.; Sarker, B.; et al. Comparative studies of mechanical and interfacial properties between jute fiber/PVC and e-glass fiber/PVC composites. Polym. Plast. Technol. Eng. 2011, 50, 153-159. [CrossRef]

17. Sheng, K.; Qian, S.; Wang, H. Influence of potassium permanganate pretreatment on mechanical properties and thermal behavior of moso bamboo particles reinforced PVC composites. Polym. Compos. 2014, 35, 1460-1465. [CrossRef] 
18. Djidjelli, H.; Boukerrou, A.; Founas, R.; Rabouhi, A.; Kaci, M.; Ferenc, J.; Martinez-Vega, J.B.; Benachour, D. Preparation and characterization of poly(vinyl chloride)/virgin and treated sisal fiber composites. J. Appl. Polym. Sci. 2007, 103, 3630-3636. [CrossRef]

19. Kamel, S. Preparation and properties of composites made from rice straw and poly(vinyl chloride) (PVC). Polym. Adv. Technol. 2004, 15, 612-616. [CrossRef]

20. Markarian, J. Wood-plastic composites: Current trends in materials and processing. Plast. Addit. Compound. 2005, 7, 20-26. [CrossRef]

21. Chaochanchaikul, K.; Rosarpitak, V.; Sombatsompop, N. Photodegradation profiles of PVC compound and wood/PVC composites under UV weathering. eXPRESS Polym. Lett. 2013, 7, 146-160. [CrossRef]

22. Shah, B.L.; Matuana, L.M. Novel coupling agents for PVC/wood-flour composite. J. Vinyl Addit. Technol. 2005, 11, 160-165. [CrossRef]

23. Wirawan, R.; Zainudin, E.S.; Sapuan, S.M. Mechanical properties of natural fibre reinforced PVC composites: A review. Sains Malaysiana 2009, 38, 531-535.

24. Maldas, D.; Kokta, B.; Daneault, C. Composites of polyvinyl chloride-wood fibers: IV. Effect of the nature of fibers. J. Vinyl Addit. Technol. 1989, 11, 90-99. [CrossRef]

25. Mengeloglu, F.; Matuana, L.; King, J. Effects of impact modifiers on the properties of rigid PVC/wood-fiber composites. J. Vinyl Addit. Technol. 2000, 6, 153-157. [CrossRef]

26. Kokta, B.V.; Maldas, D.; Daneault, C.; Beland, P. Composites of poly(vinyl chloride) and wood fibers. Part II: Effect of chemical treatment. Polym. Compos. 1990, 11, 84-89. [CrossRef]

27. Kociszewski, M.; Gozdecki, C.; Wilczyński, A.; Zajchowski, S.; Mirowski, J. Effect of industrial wood particle size on mechanical properties of wood-polyvinyl chloride composites. Eur. J. Wood Wood Prod. 2012, 70, 113-118. [CrossRef]

28. Ping, Q.W.; Xiao, J.; Zhao, J. The preparation and property of organic solvent lignin and PVC composite materials. Adv. Mater. Res. 2011, 236-238, 1195-1198. [CrossRef]

29. Feldman, D.; Banu, D. Contribution to the study of rigid PVC polyblends with different lignins. J. Appl. Polym. Sci. 1997, 66, 1731-1744. [CrossRef]

30. Saheb, D.; Jog, J.P. Natural fiber polymer composites: A review. Adv. Polym. Technol. 1999, 18, 351-363. [CrossRef]

31. Liu, F.; Xu, K.; Chen, M.; Cao, D. Thermal stability of PVC-lignin blends miscibilized by poly(ethyl acrylate-co-acrylic acid). CIESC J. 2012, 63, 3324-3329.

32. Elashmawi, I.S.; Hakeem, N.A.; Marei, L.K.; Hanna, F.F. Structure and performance of ZnO/PVC nanocomposites. Phys. B Condens. Matt. 2011, 405, 4163-4169. [CrossRef]

33. Abu-Abdeen, M. Static and dynamic mechanical properties of poly(vinyl chloride) loaded with aluminum oxide nanopowder. Mater. Des. 2012, 33, 523-528. [CrossRef]

34. Xie, X.L.; Liu, Q.X.; Li, R.K.Y.; Zhou, X.P.; Zhang, Q.X.; Yu, Z.Z.; Mai, Y.W. Rheological and mechanical properties of $\mathrm{PVC} / \mathrm{CaCO}_{3}$ nanocomposites prepared by in situ polymerization. Polymer 2004, 45, 6665-6673. [CrossRef]

35. Xiong, Ch.; Lu, S.; Wang, D.; Dong, L.; Jiang, D.D.; Wang, Q. Microporous polyvinyl chloride: Novel reactor for $\mathrm{PVC} \mathrm{CaCO}_{3}$ nanocomposites. Nanotechnology 2005, 16, 1787-1792. [CrossRef] 
36. Broza, G.; Piszczek, K.; Schulte, K.; Sterzyński, T. Nanocomposites of poly(vinyl chloride) with carbon nanotubes (CNT). Compos. Sci. Technol. 2007, 67, 890-894. [CrossRef]

37. Sterzyński, T.; Tomaszewska, J.; Piszczek, K.; Skórczewska, K. The influence of carbon nanotubes on the PVC glass transition temperature. Compos. Sci. Technol. 2010, 70, 966-969. [CrossRef]

38. Xu, B.; Zhou, Z.F.; Ge, M.L.; Pan, W.P. Glass polyvinyl chloride/montmorillonite nanocomposites: Transition temperature and mechanical properties. J. Therm. Anal. Calorim. 2004, 78, 91-100. [CrossRef]

39. Sterky, K.; Jacobsen, H.; Jakubowicz, I.; Yarahmadi, N.; Hjertberg, T. Influence of processing technique on morphology and mechanical properties of PVC nanocomposites. Eur. Polym. J. 2010, 46, 1203-1209. [CrossRef]

40. Gilbert, M.; Haghighat, S.; Chua, S.K.; Yeng, N.S. Development of PVC/silica hybrids using PVC plastisols. Macromol. Symp. 2006, 233, 198-202. [CrossRef]

41. Ulutan, S.; Balköse, D. Diffusivity, solubility and permeability of water vapor in flexible PVC/silica composite membranes. J. Membrane Sci. 1996, 115, 217-224. [CrossRef]

42. Conradi, M.; Zorko, M.; Jerman, I.; Orel, B.; Verpoest, I. Mechanical properties of high density packed silica/poly(vinyl chloride) composites. Polym. Eng. Sci. 2013, 53, 1448-1453. [CrossRef]

43. Jeamtrakull, S.; Kositchaiyong, A.; Markpin, T.; Rosarpitak, V.; Sombatsompop, N. Effects of wood constituents and content, and glass fiber reinforcement on wear behavior of wood/PVC composites. Compos. B Eng. 2012, 43, 2721-2729. [CrossRef]

44. Zhao, Y.; Wang, K.; Zhu, F.; Xue, P.; Jia, M. Properties of poly(vinyl chloride)/wood flour/montmorillonite composites: Effects of coupling agents and layered silicate. Polym. Degrad. Stabil. 2006, 91, 2874-2883. [CrossRef]

45. Deka, B.K.; Maji, T.K. Study on the properties of nanocomposite based on high density polyethylene, polypropylene, polyvinyl chloride and wood. Compos. A Appl. Sci. Manufactur. 2011, 42, 686-693. [CrossRef]

46. Yim, H.; Kim, D.S. Physical properties of PVC/aminosilane-treated wood flour/organoclay composites. Polym. Adv. Technol. 2011, 23, 1441-1445. [CrossRef]

47. Faruk, O.; Matuana, L.M. Reinforcement of rigid PVC/wood-flour composites with multi-walled carbon nanotubes. J. Vinyl Addit. Technol. 2008, 14, 60-64. [CrossRef]

48. Feldman, D.; Banu, D.; Lora, J.; El-Raghi, S. Rigid poly(vinyl chloride)-organosolv lignin blends for applications in building. J. Appl. Polym. Sci. 1996, 61, 2119-2128. [CrossRef]

49. Klapiszewski, Ł.; Nowacka, M.; Milczarek, G.; Jesionowski, T. Physicochemical and electrokinetic properties of silica/lignin biocomposites. Carbohydr. Polym. 2013, 94, 345-355.

50. Klapiszewski, Ł.; Królak, M.; Jesionowski, T. Silica synthesis by the sol-gel method and its use in the preparation of multifunctional biocomposites. Cent. Eur. J. Chem. 2014, 12, 173-184.

51. Bula, K.; Klapiszewski, Ł.; Jesionowski, T. A novel functional silica/lignin hybrid material as a potential bio-based polypropylene filler. Polym. Compos. 2015, 36, 913-922. [CrossRef]

52. Tomaszewska, J.; Sterzyński, T.; Piszczek, K. The influence of the chamber temperature in the Brabender measuring mixer on the state of equilibrium of the torque of rigid poly(vinyl chloride). Polimery 2008, 53, 678-680. 
53. Tomaszewska, J.; Sterzyński, T.; Piszczek, K. Rigid poly(vinyl chloride) gelation in a Brabender measuring mixer. III. Transformation in the torque maximum. J. Appl. Polym. Sci. 2007, 106, 3158-3164. [CrossRef]

54. Ari, G.A.; Aydin, I. A study on fusion and rheological behaviors of $\mathrm{PVC} / \mathrm{SiO}_{2}$ microcomposites and nanocomposites: The effects of $\mathrm{SiO}_{2}$ particle size. Polym. Eng. Sci. 2011, 51, 1574-1579. [CrossRef]

55. Chen, C.H.; Li, H.C.; Teng, C.C.; Yang, C.H. Fusion, electrical conductivity, thermal and mechanical properties of rigid poly(vinyl chloride) (PVC)/carbon black (CB) composites. J. Appl. Polym. Sci. 2006, 99, 2167-2173. [CrossRef]

56. Tomaszewska, J.; Sterzyński, T.; Zajchowski, S. Thermal and structural effects of poly(vinyl chloride)/(wood flour) compound gelation in the Brabender mixer. J. Vinyl Addit. Technol. 2011, 17, 239-244. [CrossRef]

57. Shimpi, N.G.; Verma, J.; Mishra, S. Preparation, characterization and properties of poly(vinyl chloride)/CaSO 4 nanocomposites. Polym. Plast. Technol. Eng. 2009, 48, 997-1001. [CrossRef]

58. Chrissafis, K.; Bikiaris, D. Can nanoparticles really enhance thermal stability of polymers? Part I: An overview on thermal decomposition of addition polymers. Themochim. Acta 2011, 523, 1-24. [CrossRef]

59. Folarin, O.M.; Sadiku, E.R. Thermal stabilizers for poly(vinyl chloride): A review. Int. J. Phys. Sci. 2011, 6, 4323-4330.

60. McNeill, I.C.; Memetea, L.; Cole, W.J. A study of the products of PVC thermal degradation. Polym. Degrad. Stabil. 1995, 49, 181-191. [CrossRef]

61. Mohamed, N.A.; Sabaa, M.W. Thermal degradation behavior of poly(vinyl chloride)-poly(vinyl butyral) blends. Eur. Polym. J. 1999, 35, 1731-1737. [CrossRef]

62. Poerschmann, J.; Weiner, B.; Woszidlo, S.; Koehler, R.; Kopinke, F.D. Hydrothermal carbonization of poly(vinyl chloride). Chemosphere 2015, 119, 682-689. [CrossRef] [PubMed]

63. Chen, G.; Tian, M.; Guo, S. A study on the morphology and mechanical properties of PVC/nano-SiO 2 composites. J. Macromol. Sci. B 2006, 45, 709-725. [CrossRef]

64. Jabbari, M.; Åkesson, D.; Skrifvars, M.; Taherzadeh, M.J. Novel lightweight and highly thermally insulative silica aerogel-doped poly(vinyl chloride)-coated fabric composite. J. Reinf. Plast. Compos. 2015. [CrossRef]

65. Czegeny, Z.; Jakab, E.; Bozi, J.; Blazso, M. Pyrolysis of wood-PVC mixtures. Formation of chloromethane from lignocellulosic materials in the presence of PVC. J. Anal. Appl. Pyrol. 2015, 113, 123-132. [CrossRef]

(C) 2015 by the authors; licensee MDPI, Basel, Switzerland. This article is an open access article distributed under the terms and conditions of the Creative Commons Attribution license (http://creativecommons.org/licenses/by/4.0/). 